\title{
La libertad religiosa en España: un breve estudio en el sistema jurídico- español
}

\section{Religious freedom in Spain: a brief study in the legal-spanish system}

(9) Salvador Morales Ferrer ${ }^{1}$

Resumen: Desde los inicios del Siglo XIX especialmente la primera Constitución Española, Cádiz avalo el catolicismo pasando por diversas Constituciones y Concordados con la Iglesia Católica, hasta llegar a la Constitución de la Segunda República donde se estableció el laicismo. Fue en la época del franquismo donde se adquirió como base central de la Nación Española la Iglesia Católica. Con la llegada de la democracia en España se promulgo la Constitución Española de 1978, por la que se promovió la laicidad de España y su libertad tanto de culto como de expresión.

Palabras Claves: Constituciones. Religión. Libertad de Culto. Expresión religiosa.

Abstract: From the beginning of the 19th century, especially the first Spanish Constitution, Cádiz endorsed Catholicism through various Constitutions and agreed with the Catholic Church, until arriving at the Constitution of the Second Republic where secularism was established. It was during the Franco era that the Catholic Church was acquired as the central base of the Spanish Nation. With the arrival of democracy in Spain, the Spanish Constitution of 1978 was promulgated, promoting the secularity of Spain and its freedom of worship and expression.

Keywords: Constitutions. Religion. Freedom of Worship. Religious expression.

Data de submissão do artigo: Abril de 2021

Data de aceite do artigo: Novembro de 2021

\footnotetext{
1 Doctor en Derecho por el programa de Estudios Jurídicos, Ciencia Política y Criminología de la Universidad de Valencia, con la calificación Apto Cum Laude Certificado-Diploma de Estudios Avanzados TERCER CICLO - DOCTORADO por la Universidad Cardenal Herrera CEU de Valencia. Certificado de Aptitud Profesional realizado en la Escuela de Práctica Jurídica del Ilustre Colegio de abogados de Alzira. Máster Propio en Mediación y Gestión Eficiente de Conflictos por la Universidad Cardenal Herrera-Ceu (Valencia). Certificado de Aptitud Pedagógica por la Universidad de Valencia. Abogado Colegiado en el ILUSTRE COLEGIO DE ABOGADOS DE ALZIRA. Letrado Especialista para actuar en la Jurisdicción de Menores. salvadormorales@icaalzira.com
} 


\section{Introducción}

Desde los inicios del Siglo XIX, España siempre fue fiel a la Iglesia Católica, apostólica, romana como mencionó la primera Constitución española la Constitución de Cádiz. A posteriori existieron otras Constituciones españolas como la Constitución de Española de 1837, que fue un poco más liberal en cuanto culto religioso se refiere. Por otro lado, la Constitución Española de 1869 garantizó la libertad de culto a las personas no católicas. Llegado el Siglo XX, la Constitución de la Segunda República se separó del culto católico atendiendo al espíritu democrático y, convirtiendo a España en un estado laico. Tras la dictadura del general Franco se involuciono adquiriendo la Iglesia Católica el eje fundamental de la Nación Española, mediante la promulgación de las Leyes del Reino y, en 1967 el régimen de Franco se flexibilizo promulgando la Ley 44/1967 de 28 de junio, regulando el ejercicio del derecho civil a la libertad en materia religiosa, aunque los ciudadanos de otros cultos no estaban suficientemente protegidos, en cambio se permitio practicar su culto escondidos. Tras la promulgación de la Constitución Española de 1978 y el desarrollo de sus normas se procedió a la libertad de culto y se volvió en cierto modo la Constitución de 1931 de la Segunda República a efectos religiosos. Con el presente artículo se pretende realizar un análisis descriptivo en los efectos jurídicos- históricos que hacen hincapié en los efectos tanto de la Religión Católica y otros cultos en España El artículo tiene la siguiente estructura: el primero esboza los antecedentes históricos Constitucionales en España, y los Concordatos con la Iglesia Católica; el segundo presenta la laicidad de la Segunda República; el tercero aclara la supremacía de la religión católica tras el mandato del General Franco, y cierta libertad de culto, la influencia de la mujer en el sistema católico y la censura respecto a las otras religiones; el cuarto atiende a la libertad de culto tras la promulgación de la Constitución de 1978; el quinto se analizan los principios informadores de la libertad de culto en la Constitución española de 1978; sexto se muestra la libre convicción religiosa; 
La libertad religiosa en España: un breve estudio en el sistema jurídico- español

séptimo se esboza la norma de libertad religiosa; el octavo trata de los acuerdos de la Iglesia Católica y las demás confesiones religiosas con arraigo en España; y finamente el noveno aclara de la inscripción y cancelación de las entidades de culto.

\section{Antecedentes históricos}

La primera Constitución Española promulgada en Cádiz a 19 de marzo de $1912^{2}$ en su artículo 12 establecía: “La religión de la Nación española es y será perpetuamente la católica, apostólica, romana, única y verdadera. La nación la protege por sus sabias y justas leyes, y prohíbe el ejercicio de cualquier otra". Por lo que, el legislador de aquella época es muy estricto respecto a las demás religiones, quizás por la Contra Reforma Luterana como menciona el autor Huesbe ${ }^{3}$ : “Como se sabe, tanto Lutero y Calvino aparecen en la historia europea como reformadores religiosos, atentos a producir una verdadera renovación de las estructuras eclesiólogicas de la Iglesia". Aunque la Constitución Española de $1812^{4}$ fue muy avanzada en su tiempo respecto a la separación de poderes como contemplaba en su artículo $3^{5}$ al señalar: "La soberanía reside esencialmente en la Nación, y por lo mismo pertenece a ésta exclusivamente el derecho de establecer leyes fundamentales". Por otro lado, la Constitución de Española de 1837 supuso un avance desvincularse con el aspecto doctrina de la Iglesia Católica , así lo señalaba en su artículo 116: “La nación se obligará á mantener el culto y los ministros de la religión católica que profesan los españoles". En cierta medida su influencia fue la causa de la desamortización que se emprendió en España. Por otro lado, hubo un acercamiento a la religión católica mediante el

\footnotetext{
2 constitución de 1812-Centro de Estudios Políticos y... www. cepc. gob. es>docs> constituciones-espa. p.2 (Visto20-10-2021) 3 Huesbe Llanos, Marco A. Reforma Política Luterana en el Siglo XVII de Martín Lutero a Henning a Arnisaeus. Universidad Católica de Valparaíso (Escuela de Derecho). Revista de Estudios-histórico - jurídicos $\left(n^{\circ} 21\right)$. Valparaíso. Ed. Pontificia Universidad Católica de Valparaíso. Facultad de Derecho, 1999.

4 Constitución de 1812-Centro de Estudios Políticos y... www. cepc. gob. es>docs> constituciones-espa. p.1. (visto20-10-2021). 5 Constitución de 1812-Centro de Estudios Políticos y... www. cepc. gob. es>docs> constituciones-espa. p.2 (visto20-10-2021) 6 Constitución de la Monarquía Española año 1837. www. congreso.es>docu> constituciones> 1837>ce37_cd.p.9 (visto20-10-2021).
} 
La libertad religiosa en España: un breve estudio en el sistema jurídico- español

Concordato 7 entre su Santidad y S.M. Católica firmado en Madrid el 16 de abril de 1854 y ratificado por S.M. el 17 de abril y por su Santidad el 23 el mismo que expresaba en su artículo 1: “La religión católica, apostólica, romana, que con exclusión de cualquiera otro culto continua siendo la única nación española, se conservará siempre en los dominios de S.M. Católica con las prerrogativas de que debe gozar según la ley De Dios y por lo dispuesto por los sagrados Cánones". Por lo que, era una confesionalidad católica de tipo excluyente, con un cierto cariz doctrinal.

Por otra parte, la Constitución Española de 1869 fue más liberal en su contenido así en su artículo $21^{8}$ señalaba: “La Nación se obliga a mantener el culto y los ministros de la religión católica. El ejercicio público o privado de cualquier otro culto queda garantido a todos los extranjeros residentes en España, sin más limitaciones que las reglas universales de la moral y del derecho. Si algunos españoles profesaren otra religión que la católica, es aplicable a los mismos todos los mismos en el supuesto anterior". Por lo que, es la primera vez que a los españoles que no son católicos puedan ejercer sus derechos.

\section{La Constitución Española de la II República de 1931}

El comienzo de la libertad religiosa se inició a raíz de la promulgación de la Constitución de $1931^{9}$ que en su artículo señalaba 3: “El Estado español no tiene religión oficial”, por lo que, el Estado Español no adopta ningún tipo de religión de carácter oficial. Del mismo modo, la Constitución Española de aquella época en su artículo $27.1^{10}$ establecía: “La libertad de conciencia y el derecho de profesar y practicar libremente cualquier religión

\footnotetext{
7 Gaceta de Madrid. Presidencia Consejo de Ministros. Lunes 12 de mayo de 1854. № 6146. p.1.www.boe.es>datos>pdfs $>$ BOE $>1851$. (visto-22-102019)

8 Constitución Democrática de la Nación Española. Promulgada el día 8 de junio de 1869. p. 3. www. cepc. gob. es>docs> constituciones>espa>1869 (visto 23-10-2019)

9 Constitución de la Segunda República de 1931. p.1 www. congreso. es>docu> constituciones>1931>1931_cd (visto23-10-2019) 10 Constitución de la Segunda República de 1931. p.10 www.congreso.es>docu> constituciones>1931>1931-cd (visto23-10-2019)
} 
La libertad religiosa en España: un breve estudio en el sistema jurídico- español

quedan garantizados en el territorio español". De esta forma, como menciona la autora Moreno11: "El gobierno republicano era heredero del pensamiento del pensamiento progresista decimonónico que vinculaba el laicismo al progreso de la nación". Por lo que, el gobierno tiende a una clara libertad democrática en asuntos religiosos.

\subsection{La Constitución Española de la II República y sus ca- racterísticas en las distintas religiones}

A pesar de que se proclamará la libertad de culto en la Segunda República Española como bien indica el artículo 27. $3^{12}$ da la Constitución señalaba: "Todas las confesiones podrán ejercer sus cultos privadamente, Las manifestaciones públicas podrán del culto habrán de ser, en su caso, autorizadas por el Gobierno. Nadie podrá ser compelido a declarar oficialmente sus creencias religiosas", por lo cual todo tipo de Iglesias, o, culto estaban prohibidos, sino eran autorizados por el gobierno de la República, tanto católicos, cristianos $u$, otras confesiones religiosas. Por otro lado, estaba prohibido que los ciudadanos les obligarán a definir su religión por lo que había un cierto temor social a la libertad de expresión y en consecuencia sus cultos o, iglesias religiosas.

Por otra parte, cabe mencionar el mismo artículo $27.3^{13}$ de la misma Constitución que expresa: "La condición religiosa no constituirá circunstancia modificativa de la personalidad civil, ni política", por lo que extrayendo de este texto supone que se admiten todo tipo de creencias religiosas en cuanto a la personalidad civil puesto que los sacerdotes católicos no se pueden casar, mientras la otros cultos si se pueden casar ejemplo los pastores evangélicos, al mismo tiempo la expresión política da entender que tampoco influirían en las distintas opciones políticas.

\footnotetext{
11 Moreno Seco, Mónica. “La política religiosa y la educación laica en la Segunda República. Pasado y Memoria. Revista de historia Contemporánea. Universidad del País Vasco, 2003, p. 83.

12 Constitución de la Segunda República de 1931. p.1 www. congreso. es>docu> constituciones>1931>1931_cd (visto23-10-2019) 13 Constitución de la Segunda República de 1931. p.1 www. congreso. es>docu> constituciones>1931>1931_cd (visto23-10-2019)
} 


\section{La Religión tras la llegada del Régimen franquista}

Tras el fin de la Segunda República Española, vino la dictadura franquista supuso el eje Iglesia- Estado, volviendo a la involución de las libertades religiosas y, el comienzo de la confesionalidad del Estado Español por lo que se promovió el "nacional- catolicismo". Y así, se promulgaron las Ilamadas "Leyes Fundamentales del Reino"14 que en su artículo sexto señalaba: “La profesión y práctica de la Religión Católica, que es la del Estado español, gozará de la protección oficial. El Estado asumirá la protección de la libertad religiosa, que será garantizada por su eficaz tutela jurídica que, a la vez, salvaguarde la moral y el orden público", y, en su artículo treinta y tres de la misma norma manifestaba: "El ejercicio de los derechos que se reconocen en este Fuero no podrá atentar a la unidad espiritual, nacional y social de España". Por lo tanto, la unidad de España se basaba especialmente en la Iglesia Católica. Por otro lado, cabe mencionar El Fuero de los Españoles de $1945^{15}$ en su artículo sexto señalaba: “La profesión y práctica de la Religión Católica que es la del Estado Español, gozará de la protección oficial. Nadie será molestado por sus creencias religiosas ni el ejercicio privado de su culto. No se permitirán otras ceremonias ni manifestaciones externas que las de la Religión Católica". Por lo tanto, estaban prohibidos otros cultos sí eran manifiestamente públicos, aunque en este sentido existía una flexibilidad.

\subsection{La Confesionalidad religiosa de España y la libertad de culto}

En los Fueros de los Españoles concretamente en la Ley Principios Fundamentales del Movimiento en su Exposición de

\footnotetext{
14 Decreto779/1962, de 20 de abril por el que se aprueban sobre los textos Refundidos de las Leyes del Reino Ley Fundamentales del Reino I. Disposiciones Generales. Boletín Oficial del Estado (BOE) Madrid. N. Boletín:95. p.5253.. https: // www. boe. es>boe>días>1967/04/21 >pdfs (visto 23-10-2019)

15 Fuero de los Españoles de julio de 1945. Jefatura del Estado. Boletín Oficial del Estado (BOE) Madrid. N. Boletín:199. p.358. https: // www. boe.es>datos>pdfs>BOE>1945. (visto 23-10-2019)
} 
La libertad religiosa en España: un breve estudio en el sistema jurídico- español

Motivos II ${ }^{16}$ señalaba: " La Nación Española considera timbre de honor el acatamiento a la Ley de Dios, según la doctrina de la Santa Iglesia Católica, Apostólica y Romana, única y verdadera fe, inseparable de la consciencia nacional, que inspira su legislación", por lo que, la legislación franquista acataba la religión católica incluso a efectos de separaciones matrimoniales y la desigualdad del hombre y la mujer. Al mismo tiempo, existió el Convenio ${ }^{17}$ entre la Santa Sede y el Gobierno de España que en su artículo 6 señalaba: "El Gobierno español, por su parte, se compromete formalmente a concluir cuanto antes con la Sata Sede un nuevo concordato, inspirado en el deseo de restaurar el sentido católico de la gloriosa tradición nacional". Por lo que, se creaba una cierta intolerancia respecto a las otras confesiones religiosas. Al respecto el gobierno franquista con la Santa Sede cristalizó la religión católica mediante el nuevo Concordato de $1953^{18}$, basado en el sistema de Derecho Público en este sentido cabe mencionar su artículo 1 que señalaba: “La religión católica, Apostólica sigue siendo la única Nación española y gozará de derechos y de las prerrogativas que le corresponden en conformidad en la Ley Divina y el Derecho Canónico". Por lo cual, se establece un reconocimiento a la jurisdicción católica y, competencia respecto a los matrimonios o, educación. Al mismo tiempo, cabe mencionar la Ley 44/1967 de 28 de junio, regulando el ejercicio del derecho civil a la libertad en materia religiosa ${ }^{19}$ en su artículo segundo Uno señala: "El derecho a la libertad no tendrá más limitaciones que las derivadas que el acatamiento a las Leyes; del respeto a la Religión Católica, que es de la Nación española y las otras confesiones religiosas: a la moral ajenos, como las exigencias del orden público". Por tanto se les daba un poco de libertad a otras religiones que no eran católicas siempre que no atentarán a la moral y el orden público", de esta

\footnotetext{
16 Decreto779/1962, de 20 de abril por el que se aprueban sobre los textos Refundidos de las Leyes del Reino Ley Fundamentales del Reino I. Disposiciones Generales. Boletín Oficial del Estado (BOE) Madrid. N. Boletín:95. p.5253. https: // www. boe. es>boe>días>1967/04/21>pdfs (visto 23-10-2019.)

17 Convenio entre la Santa Sede y el Gobierno de España (7 de junio de 1941) p.1.www.. fuenterrebo>Textos.- Legales>santa -sede-estado (visto23-10-2019)

18 Concordato de 1953 entre España y la Santa Sede. p.1.www.vatican.va.>documents>rc_seg-st_19530827_concordato-spagna_sp (visto23-102019).

19 Ley 44/1967 de 28 de junio, regulando el ejercicio del derecho civil a la libertad en materia religiosa. I Disposiciones Generales Boletín Oficial del Estado (BOE) Madrid. N. Boletín:156. p.9192. DOCUMENTO BOE-A-1967-10943. BOE.es. htps://www.boe.es> Buscar (Derogado)
} 
La libertad religiosa en España: un breve estudio en el sistema jurídico- español

forma queda reflejado en las Leyes Penales ${ }^{20}$ en su artículo 209 señala: "El que de palabra o por escrito hiciere escarnio de la religión católica o de confesión reconocida legalmente, o ultrajare públicamente sus dogmas, ritos o ceremonias, será castigado con pena de prisión menor si realizase el hecho en actos de culto, o, en lugar destinado a celebrarlos y con arresto mayor en los demás casos", en el artículo 1.Dos de la Ley 44/1967 de 28 de junio, regulando el ejercicio del derecho civil a la libertad en materia religiosa ${ }^{21}$ menciona: "La profesión y práctica privada y pública de cualquier religión será garantizada por el Estado". Al respecto la autora García ${ }^{22}$ manifiesta" La distinción y autonomía de ambas potestades se conjuga siempre con una operación de intereses comunes, que viene exigida por las mismas relaciones del derecho y hecho existente durante esa época". Por tanto, en esta época del franquismo era España confesional, pero, también existían otros cultos siempre que estuvieran registrados en España.

\subsection{La mujer en la época de Franco y su sumisión a la Iglesia}

En este sentido, no hay que olvidar el papel de la mujer en esta época franquista la denominada "sección femenina" sus valores fundamentales eran los siguientes: $1^{\circ}$ Sumisión respetuosa y amorosa a la Jerarquía de la iglesia, cuyas direcciones y consejos será sagrados para ellas. 2 orientación hacia la parroquia, casa del cristiano donde Dios derrama sus gracias con especial solicitud. Orientación de las muchachas y mujeres de la parroquia como casa donde todos los cristianos deben ver su hogar. 3 preocupación por la liturgia oración autentica de la Iglesia. Por lo que, las mujeres transmitirán esa religión que avalará la causa de Franco y

20 Leyes Penales (1976) Editorial Civitas S.A. Madrid.p75 (Derogado)

21 Ley 44/1967 de 28 de junio, regulando el ejercicio del derecho civil a la libertad en materia religiosa. I Disposiciones Generales Boletín Oficial del Estado (BOE) Madrid. N. Boletín:156. p.9192 BOE DOCUMENTO BOE-A-1967-10943. BOE.es. htps://www.boe. es> Buscar (Derogado)

22 García Balart, Nuria. Confesionalidad, Tolerancia y Libertad Religiosa en la Doctrina del episcopado español (1953-1968). Editorial Universidad de Navarra, 2003, p.7. 
La libertad religiosa en España: un breve estudio en el sistema jurídico- español

asegurará inamovilidad de los principios que garantizarán que no se romperá su imagen diferente a la del hombre que no se caerá del pedestal al que subió en el Evangelio, al hilo cabe mencionar a la autora Pérez ${ }^{23}$ que manifiesta: "La Organización Femenina del SEU, como Regiduría Central de la Sección Femenina, no se organizó hasta después de la Cruzada, y funcionó a caballo entre la Sección Femenina y el SEU propiamente dicho. A partir de 1944, la Sección Femenina del SEU quedó definitivamente acoplada y estructurada, quedando vinculada: A la Sección Femenina del Movimiento, en lo que se refería a la formación de la universitaria como mujer y como española, tarea encomendada por Decreto a la Delegada Nacional de la Sección Femenina" y añade la autora "Ayuda Universitaria, Intercambio cultural, Formación Profesional". Por lo cual, la sección femenina fue un eje del Estado franquista vinculado a la Iglesia Católica.

\subsection{La censura en el Régimen Franquista}

En aquella época solo se limitaban a los libros de la religión católica como principal pilar del Estado Español por lo que se promovió la censura a los demás cultos religiosos la propagación de sus textos sagrados al hilo cabe mencionar a la autora Meseguer ${ }^{24}$ que manifiesta: "El franquismo se instauró a base de medidas represivas, orientadas a acallar voces disidentes y a imponer una ideología autoritaria y católica. Durante los primeros años de la dictadura, se llevó a cabo una especie de purga intelectual, con el encarcelamiento de autores y editores, el cierre de editoriales y la destrucción de manuscritos". Por otro lado, el autor Sinova 25 manifiesta:" En realidad, los responsables del control de la Prensa no empezaron a ejercer hasta enero de 1946". Por lo cual, se propició que solo existieran libros de la Doctrina Católica. Aunque

\footnotetext{
23 Pérez García, María Pilar. La Sección Femenina del Seu. Editorial FNFF Mardrid, 2019, p.3.

24 Meseguer, Purificación. La traducción como arma de propagandística: censura de Orwell, Abelio y Kloester en la España franquista. Editorial Universidad de Murcia, 2015, p.110.

25 Sinova, Justino. La censura de prensa durante el franquismo. Editorial Espasa Calpe.S..A. Barcelona, 2006, p.125.
} 
La libertad religiosa en España: un breve estudio en el sistema jurídico- español

a partir de la Ley 44/1967 de 28 de junio, regulando el ejercicio del derecho civil a la libertad en materia religiosa ${ }^{26}$ en su artículo segundo Uno señala: "El derecho a la libertad no tendrá más limitaciones que las derivadas que el acatamiento a las Leyes; del respeto a la Religión Católica, que es de la Nación española y las otras confesiones religiosas: a la moral ajenos, como las exigencias del orden público". Por tanto, se les daba un poco de libertad a otras religiones que no eran católicas siempre que no atentarán a la moral y el orden público" estaban permitidos otros cultos, no así estaba la censura cuando se menciona "a la moral ajenos, como las exigencias del orden público", lo que implicaba la censura de los textos de otras confesiones.

\section{La libertad religiosa tras la promulgación de la Constitución Española de 1978}

Una vez publicada la Constitución de 1978, se realizó un gran cambio en nuestro ordenamiento jurídico español, configurándose España como un Estado Social y Democrático como menciona el artículo 1.127 de la Constitución Española de 1978: “España se constituye en un Estado social y democrático de Derecho, que propugna como valores superiores de su ordenamiento jurídico la, la libertad, la justicia, la igualdad y el pluralismo político". Por tanto, supuso una quiebra del régimen franquista y un nuevo comienzo de España Estado democrático. Estos principios informadores del Estado Español están concebidos en la Constitución Española en el artículo $16.1^{28}$ que señala: "Se garantizará la libertad ideológica, religiosa y de culto de los individuos y las comunidades sin más limitaciones en sus manifestaciones, que la necesaria para el mantenimiento del orden público protegido por la ley". Por tanto, se reconoce la libertad de culto. Por otro lado, cabe mencionar

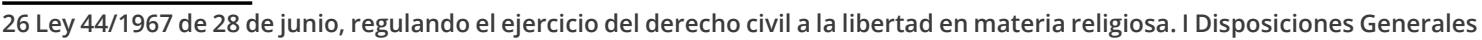
Boletín Oficial del Estado (BOE) Madrid. N. Boletín:156. p.9192. DOCUMENTO BOE-A-1967-10943. BOE.es. htps://www.boe.es> Buscar (Derogado)

27 Constitución Española (2003) Editorial Aranzadi. S.A. Cizur Menor (Navarra). p.60.

28 Constitución Española. Op. Cit., p.70. 
La libertad religiosa en España: un breve estudio en el sistema jurídico- español

el artículo $14^{29}$ que señala: " Los españoles son iguales ante la ley, sin que pueda prevalecer discriminación alguna por razón de religión", así mismo se reconoce la laicidad del Estado Español y el artículo $16.3^{30}$ de la Constitución señala: “Ninguna confesión tendrá carácter estatal ", por lo que cabe decir que España es un Estado aconfesional y laico, a todo esto cabe mencionar que esta artículo vuelve a la Constitución de la Segunda República española1931'11 que en su artículo señalaba 3: “El Estado español no tiene religión oficial". Por lo cual, supuso un cambio radial de confesionalidad religiosa en España mediante la proclamación de la Constitución de 1978.

\section{Los principios informadores de religión en el sistema jurídico español}

La Constitución española es muy esclarecedora en este sentido así cabe mencionar los artículos siguientes el artículo $1.1^{32}$ señala: '“'España se constituye en un Estado social y democrático de Derecho, que propugna como valores superiores de su ordenamiento jurídico la, la libertad, la justicia, la igualdad y el pluralismo político". Por lo que puede deducirse la libertad religiosa, el artículo 9.2 del mismo texto legal manifiesta: "Corresponde a los poderes públicos promover las condiciones para que la libertad y la igualdad del individuo y los grupos en que se integra sean reales y efectivas; remover los obstáculos que impidan o dificulten su plenitud y facilitar la participación de todos los ciudadanos". Por lo que representa la cooperación en el ámbito religioso. Y el artículo $10.2{ }^{33} \mathrm{del}$ mismo cuerpo legal manifiesta: "Las normas a los derechos fundamentales y a las libertades que la Constitución reconoce se interpretarán de conformidad en

\footnotetext{
29 Constitución Española. Op. Cit., p.69. 30 Constitución Española. Op. Cita., p 71 31 Constitución de la Segunda República de 1931. p.1 www. congreso. es>docu> constituciones>1931>1931_cd 32 Constitución Española. Op. Cit., p.60 33 Constitución Española. Op. Cit., p.65
} 
La libertad religiosa en España: un breve estudio en el sistema jurídico- español

la Declaración Universal de los Derechos Humanos y tratados y acuerdos internacionales sobre la misma materia ratificados en por España". Por lo cual, la Constitución Española establece Derecho Internacional así la Declaración Internacional de Derechos Humanos aclar en su artículo 1934: “Todo individuo tiene derecho a la libertad de opinión y de expresión; este derecho incluye el de no ser molestado a causa de sus opiniones, el de investigar y recibir informaciones y opiniones, y el de difundirlas, sin limitación de fronteras, por cualquier medio de expresión", y también hay que recordar el artículo $14.1^{35}$ se la Constitución española que señala: “ Los españoles son iguales ante la ley, sin prevalecer discriminación alguna por razón de religión" y el mismo texto legal en su artículo $16.1^{36}$ señala: "Se garantiza la libertad religiosa y el culto de los individuos", por lo que, España es un estado laico donde se permiten todas las religiones siempre que estén registradas en el Ministerio de Justicia de España.

\title{
6. El derecho en España como elemento fundamental como libre convicción religiosa
}

\begin{abstract}
El Tribunal Supremo en España ${ }^{37}$ en su Sentencia del 1305-1982 en sus antecedentes de derecho a) señala:" El sistema instaurado por la Constitución en la materia de las relaciones entre la Iglesia y el Estado y de la posición del Estado en relación con las religiones, ha representado una ruptura de gran importancia, porque de una parte, la plena libertad ideológica y religiosa ha sustituido a la simple tolerancia; y de otra, se ha dado paso a la proclamación de que ninguna confesión tiene carácter de estatal". De esta manera, de manera que se reconoce la facultad a toda persona a actuar en este campo con plena inmunidad de coacción
\end{abstract}

\footnotetext{
34 La declaración Universal de Derechos Humanos 10 de diciembre de 1948. p.3. https://dudlh.es 35 Constitución Española. Op. Cit., p.69.

36 Constitución Española. Op. Cit.., p. 71.

37 Tribunal Constitucional (Pleno) (Ponente: Diez- Picazo y Ponce de León , Luis) (Sentencia núm.24/1982 de 7 de febrero). Rec. $68 / 1982$ Lefebvre.
} 
La libertad religiosa en España: un breve estudio en el sistema jurídico- español

por parte de los poderes públicos y de cualesquiera otra persona o grupo social. Por tanto, España es un estado laico en materia religiosa.

\section{La ley Orgánica 7/1980, de 5 de julio, de libertad religiosa}

Una vez el legislador español plasmó en la Constitución Española de 1978 las libertades de los ciudadanos en cuanto a libertad religiosa, también promulgo esta ley por lo que es muy clarificadora así en la Ley orgánica 7/1980, de 5 de julio, de libertad religiosa en su artículo primero ${ }^{38}$ señala: "El Estado garantiza el derecho fundamental a la libertad religiosa y de culto, reconocida en la Constitución, de acuerdo con lo prevenido en la presente Ley Orgánica. Las creencias religiosas no constituirán motivo de desigualdad o discriminación ante la Ley. No podrán alegarse motivos religiosos para impedir a nadie el ejercicio de cualquier trabajo o actividad o el desempeño de cargos o funciones públicas. Ninguna confesión tendrá carácter estatal". Por lo cual reconoce la libertad religiosa y al mismo tiempo los ministros o representante de las Iglesias no podrán impedir su cargo, y lo más importante España es un estado laico. Ysu artículo segundo ${ }^{39}$ es más clarificante en las prácticas religiosas de esta forma señala: “Uno. La libertad religiosa y de culto garantizada por la Constitución comprende, con la consiguiente inmunidad de coacción, el derecho de toda persona a: a) Profesar las creencias religiosas que libremente elija o no profesar ninguna; cambiar de confesión o abandonar la que tenía; manifestar libremente sus propias creencias religiosas o la ausencia de las mismas, o abstenerse de declarar sobre ellas.; b) Practicar los actos de culto y recibir asistencia religiosa de su propia confesión; conmemorar sus festividades, celebrar sus ritos matrimoniales; recibir sepultura digna, sin discriminación

38 Ley orgánica 7/1980, de 5 de julio, de libertad religiosa. Jefatura del Estado I Disposiciones generales Boletín Oficial del Estado (BOE) Madrid. N. Boletín 177. p.15955. Documento BOE- A-1980-15955- BOE.es. htps: //www.boe.es>buscar

39 Ley orgánica 7/1980, de 5 de julio, de libertad religiosa. Jefatura del Estado I Disposiciones generales Boletín Oficial del Estado (BOE) Madrid. N. Boletín 177. p.15955 Documento BOE- A-1980-15955- BOE.es. htps: //www.boe.es>buscar 
La libertad religiosa en España: un breve estudio en el sistema jurídico- español

por motivos religiosos, y no ser obligado a practicar actos de culto o a recibir asistencia religiosa contraria a sus convicciones personales: c) Recibir e impartir enseñanza e información religiosa de toda índole, ya sea oralmente, por escrito o por cualquier otro procedimiento; elegir para sí, y para los menores no emancipados e incapacitados, bajo su dependencia, dentro y fuera del ámbito escolar, la educación religiosa y moral que esté de acuerdo con sus propias convicciones; d) Reunirse o manifestarse públicamente con fines religiosos y asociarse para desarrollar comunitariamente sus actividades religiosas de conformidad con el ordenamiento jurídico general y lo establecido en la presente Ley Orgánica; Dos. Asimismo comprende el derecho de las Iglesias, Confesiones y Comunidades religiosas a establecer lugares de culto o de reunión con fines religiosos, a designar y formar a sus ministros, a divulgary propagar su propio credo, y a mantener relaciones con sus propias organizaciones o con otras confesiones religiosas, sea en territorio nacional o en el extranjero" Por lo que se extrae lo siguiente de la norma todos según sus creencias tienen derecho a practícalas en sus colegios, ritos matrimoniales $\mathrm{y}$, especialmente a reunirse en sus cultos religiosos. Por otro lado es importante el artículo Segundo ${ }^{40}$ Tres de la misma norma pues señala lo siguiente: “Para la aplicación real y efectiva de estos derechos, los poderes públicos adoptarán las medidas necesarias para facilitar la asistencia religiosa en los establecimientos públicos, militares, hospitalarios, asistenciales, penitenciarios y otros bajo su dependencia, así como la formación religiosa en centros docentes públicos" A todo esto las distintas confesiones pueden obtener asistencia en hospitales, centros militares y docentes. Por lo que, esta norma legal orgánica que ofrece un ámbito especial de un derecho, en este caso, especificando de libertad religiosa,

40 Ley orgánica 7/1980, de 5 de julio, de libertad religiosa. Jefatura del Estado I Disposiciones generales Boletín Oficial del Estado (BOE) Madrid. N. Boletín 177. p.15955 Documento BOE- A-1980-15955- BOE.es. htps: //www.boe.es>buscar 


\section{El Derecho al pacto religioso en la actualidad en Es- paña}

En este momento en España determinado por los Acuerdos que el Estado ha celebrado hasta ahora con determinadas confesiones religiosas, en concreto cuatro, y que viene delimitado porque éstas han alcanzado "notorio arraigo" en España, amén de la capacidad potestativa por parte de las autoridades estatales de llevarlos a término así cabe mencionar a la Iglesia Católica mediante Instrumento de Ratificación del Acuerdo entre el Estado Español y la Santa Sede sobre asuntos jurídicos ${ }^{41}$ en sus artículos 11 párrafo -2 párrafo que señala: “El Estado español reconoce a la Iglesia Católica el derecho de ejercer su misión apostólica y le garantiza el libre y público ejercicio de las actividades que le son propias y en especial las de culto, jurisdicción y magisterio. La Iglesia puede organizarse libremente". Lo que indica que la Iglesia Católica podrá actual libremente, podrá sin la dependencia del Estado Español. Al mismo tiempo, cabe mencionar el acuerdo con la Comunidad Evangélica en la Ley 24/1992, del 10 de noviembre, por la que se aprueba el Acuerdo de Cooperación del Estado con la Federación de Entidades Religiosas Evangélicas de España ${ }^{42}$ en su artículo 1-1 párrafo, 3 párrafo señala: “Los derechos y obligaciones que se deriven de la Ley por la que se apruebe el presente Acuerdo serán de aplicación a las Iglesias que, figurando inscritas en el Registro de Entidades Religiosas, formen parte o se incorporen posteriormente a la Federación de Entidades Religiosas Evangélicas de España, mientras su pertenencia a la misma figure inscrita en el mencionado Registro. La certificación de fines religiosos, que exige el Real Decreto 142/1981, de 9 de enero, para la inscripción de las entidades asociativas religiosas que se constituyan como tales de acuerdo con el ordenamiento de las Iglesias evangélicas, podrá

\footnotetext{
41 Instrumento de Ratificación del Acuerdo entre el Estado Español y la Santa Sede sobre asuntos jurídicos, firmado el 3 de enero de 1979 en la Ciudad del Vaticano Jefatura del Estado I. Disposiciones generales. Boletín Oficial del Estado (BOE) Madrid. N. Boletín 300. p.29489 Documento BOE- A-1979-29489 BOE.es. htps: //www.boe.es>buscar

42 Ley 24/1992, del 10 de noviembre, por la que se aprueba el Acuerdo de Cooperación del Estado con la Federación de Entidades Religiosas Evangélicas de España Jefatura del Estado I. Disposiciones generales. Boletín Oficial del Estado (BOE) Madrid. N. Boletín 272. p.24873 Documento BOE- A-1992-24853 BOE.es. htps: //www.boe.es>buscar
} 
La libertad religiosa en España: un breve estudio en el sistema jurídico- español Salvador Morales Ferrer

ser expedida por la Comisión Permanente de la FEREDE", por lo que las Iglesias evangélicas tendrán que ser inscritas y a portar su finalidad religiosa en España. Del mismo modo las Comunidades Israelitas deben cumplir los mismos requisitos así la Ley 25/1992, de noviembre, por la que se aprueba el Acuerdo de Cooperación del Estado con la Federación de Comunidades Israelitas en España ${ }^{43}$ como menciona su artículo 1. 1 párrafo: "Los derechos y obligaciones que se deriven de la Ley por la que se apruebe el presente Acuerdo serán de aplicación a las Comunidades Israelitas que, figurando inscritas en el Registro de Entidades Religiosas, formen parte o posteriormente se incorporen a la Federación de Comunidades Israelitas de España, mientras su pertenencia a la misma figure inscrita en el mencionado Registro y finalmente cabe mencionar la Comunidad musulmana muy arraigada en España así la Ley 26/1992, de 10 de noviembre, por la que se aprueba al Acuerdo de Cooperación del Estado con la Comisión Islámica de España ${ }^{44}$ en su artículo 1 señala: “Los derechos y obligaciones que se deriven de la Ley por la que se apruebe el presente Acuerdo serán de aplicación a las Comunidades Islámicas inscritas en el Registro de Entidades Religiosas, que formen parte o posteriormente se incorporen a la «Comisión Islámica de España» o a alguna de las Federaciones Islámicas inscritas integradas en dicha Comisión, mientras su pertenencia a las mismas figure inscrita en dicho Registro" Por lo que, lo mismo que en las demás confesiones religiosas deberán inscritas en el Registro del Ministerio de Justicia, al hilo el artículo 2 señala:" A todos los efectos legales, son Mezquitas o lugares de culto de las Comunidades Islámicas pertenecientes a la «Comisión Islámica de España» los edificios o locales destinados de forma exclusiva a la práctica habitual de la oración, formación o asistencia religiosa islámica, cuando así se certifique por la Comunidad respectiva, con la conformidad de dicha Comisión", Por lo que se extrae del citado precepto legal que

\footnotetext{
43 Ley 25/1992, de noviembre, por la que se aprueba el Acuerdo de Cooperación del Estado con la Federación de Comunidades Israelitas en España Jefatura del Estado I. Disposiciones generales. Boletín Oficial del Estado (BOE) Madrid. N. Boletín 272. p.38212 Documento BOE- A- A-1992-24854 BOE.es. htps: //www.boe.es>buscar

44 Ley 26/1992, de 10 de noviembre, por la que se aprueba al Acuerdo de Cooperación del Estado con la Comisión Islámica de España. Jefatura del Estado I Disposiciones generales Boletín Oficial del Estado (BOE) Madrid. N. Boletín 272.p.38215 Documento BOE- A-1992-24875 BOE.es. htps: //www.boe.es>buscar
} 
La libertad religiosa en España: un breve estudio en el sistema jurídico- español

será reconocidas las Mezquitas y otros centros de culto siempre que estén avalados por la Comisión Islámica , por otro lado se crean cementerios musulmanes como especifica en el artículo 2 párrafo 5 al señalar: " Los cementerios islámicos gozarán de los beneficios legales que establece el número 2 de este mismo artículo para los lugares de culto" con lo que se entiende que son lugares sagrados". Por tanto, en la actualidad hay variedad de cultos siempre que se hayan inscrito en el Registro de Entidades Religiosas en España.

\section{La inscripción de los distintos cultos y su cancelación religiosos en España}

Como bien indica Ley orgánica 7/1980, de 5 de julio, de libertad religiosa ${ }^{45}$ en su artículo quinto Uno: "Las Iglesias, Confesiones y Comunidades religiosas y sus Federaciones gozarán de personalidad jurídica una vez inscritas en el correspondiente Registro público, que se crea, a tal efecto, en el Ministerio de Justicia". Por tanto, si no están inscritas las distintas confesiones no gozarán de personalidad jurídica lo que indica que no tendrán este elemento jurídico para ser reconocidos en el territorio español. Por otro lado, es interesante saber la forma de inscripción como entidad religiosa bien en forma de Iglesia, Comunidad religiosa o, federación religiosa en este sentido cabe mencionar el artículo quinto Dos"6: "La inscripción se practicará en virtud de solicitud, acompañada de documento fehaciente en el que consten su fundación o establecimiento en España, expresión de sus fines religiosos, denominación y demás datos de identificación, régimen de funcionamiento y órganos representativos, con expresión de sus facultades y de los requisitos para su válida designación". Por lo cual, se tendrá que aportar documentación fehaciente con sus fines religiosos, funcionamiento y órganos para su establecimiento

45 Ley orgánica 7/1980, de 5 de julio, de libertad religiosa. Jefatura del Estado I Disposiciones generales Boletín Oficial del Estado (BOE) Madrid. N. Boletín 177. p15956 Documento BOE- A-1980-15955 BOE.es. htps: //www.boe.es>buscar

46 Ley orgánica 7/1980, de 5 de julio, de libertad religiosa. Jefatura del Estado I Disposiciones generales Boletín Oficial del Estado (BOE) Madrid. N. Boletín 177. p15956 Documento BOE- A-1980-15955- BOE.es. htps: //www.boe.es>buscar 
La libertad religiosa en España: un breve estudio en el sistema jurídico- español

en España. Y finalmente la extinción de la Iglesia Comunidad religiosa o federación así cabe mencionar el mismo artículo 5 tres $^{47}$ que señala: "La cancelación de los asientos relativos a una determinada Entidad religiosa sólo podrá llevarse a cabo a petición de sus órganos representativos o en cumplimiento de sentencia judicial firme". Por otro lado, la nueva normativa es más concreta así cabe mencionar el Real Decreto 594/2015, de 3 de julio, por el que se regula el Registro de Entidades Religiosas ${ }^{48} \mathrm{en}$ su artículo 19 señala: "1. La cancelación de la inscripción de una entidad sólo podrá efectuarse: a) A petición de sus representantes legales debidamente facultados.; b) En cumplimiento de sentencia judicial firme; 2. La cancelación producirá efectos desde la fecha de su resolución y dará lugar al traslado de la entidad a la Sección Histórica del Registro". Por lo que la cancelación de la entidad religiosa se efectuará por sus representantes, por sentencia judicial y finalmente quedará archivado en el registro de Entidades Religiosas haciendo constancia de que ha existido y sus motivos de cancelación.

\section{Conclusiones}

1. La Constitución Española de 1912 promovió el catolicismo incluso en las colonias que poseía.

2. Las demás Constituciones españolas fueron en cierto modo flexibles con las personas no católicas, aunque influyeron en cierto modo los concordados con la Santa Sede.

3. Durante el periodo de la Segunda República Española en su Constitución de la Segunda República se promovió el laicismo en España,

4. El Régimen franquista promovió como eje central el catolicismo junto con los Concordato con la Santa Sede de 1953.

47 Ley orgánica 7/1980, de 5 de julio, de libertad religiosa. Jefatura del Estado I Disposiciones generales Boletín Oficial del Estado (BOE) Madrid. N. Boletín 177. p15956 Documento BOE- A-1980-15955- BOE.es. htps: //www.boe.es>buscar

48 Real Decreto 594/2015, de 3 de julio, por el que se regula el Registro de Entidades Religiosas. Ministerio de Justicia I Disposiciones generales Boletín Oficial del Estado (BOE) Madrid. N. Boletín 183.p.66731. Documento BOE- A-2015-8643- BOE.es. htps: // www.boe.es> Calendario>01-08-2015. 
La libertad religiosa en España: un breve estudio en el sistema jurídico- español

5. La Sección femenina fue uno de los pilares del gobierno franquista en promover los valeres de las mujeres en la Religión Católica

6. Aunque la Ley $44 / 1967$ de 28 de junio, regulando el ejercicio del derecho civil a la libertad en materia religiosa, permitió en cierto modo las otras confesiones religiosas, existió la censura en el régimen franquista, también respecto a las publicaciones de otros cultos por ir contra la moral y el orden público.

7. Durante el periodo de 1967, el régimen franquista fue más flexible respecto a las personas no católicas permitiendo realizar su culto.

8. Tras la promulgación de la Constitución de 1978, se promovió la libertad de culto e incluso el ser España un país laico, en este aspecto algo parecido a la Constitución Española de la Segunda República.

9. Todos los cultos en España deben registrase en el Ministerio de Justicia, para adquirir personalidad Jurídica.

10. Todos los cultos en España pueden cancelarse mediante sus representantes $\mathrm{o}$, sentencia judicial firme.

11. Por lo tanto, es un sistema normativo que nos sitúa ante un modelo de relación que puede ser calificado como de laicidad positiva y ante una tipificación de las entidades religiosas en España de carácter plural y diverso.

\section{Referências bibliográficas}

\section{Autores}

García Balart, Nuria. Confesionalidad, Tolerancia y Libertad Religiosa en la Doctrina del episcopado español (1953-1968). Editorial Universidad de Navarra, 2003. 
La libertad religiosa en España: un breve estudio en el sistema jurídico- español

Huesbe Llanos, Marco A. Reforma Política Luterana en el Siglo XVII de Martín Lutero a Henning a Arnisaeus. Universidad Católica de Valparaíso (Escuela de Derecho). Revista de Estudioshistórico jurídicos ( $\left.{ }^{\circ} 21\right)$. Valparaíso. Ed. Pontificia Universidad Católica de Valparaíso. Facultad de Derecho, 1999.

Pérez García, María Pilar. La Sección Femenina del Seu. Editorial FNFF Madrid, 2019.

Meseguer, Purificación. La traducción como arma de propagandística: censura de Orwell, Abelio y Kloester en la España franquista. Editorial Universidad de Murcia, 2015.

Moreno Seco, Mónica. La política religiosa y la educación laica en la Segunda República. Pasado y Memoria. Revista de historia Contemporánea. Universidad del País Vasco, 2003.

Sinova, Justino. La censura de prensa durante el franquismo. Editorial Espasa Calpe. S..A. Barcelona, 2006.

\section{Constituciones Españolas}

Constitución de 1812-Centro de Estudios Políticos y... www. cepc. gob. es>docs> constituciones-espa. p.2 (Visto20-10-2021)

Constitución de la Monarquía Española año 1837. www. congreso.es>docu> constituciones>1837>ce37_cd.p.9 (visto20-10-2021).

Constitución Democrática de la Nación Española. Promulgada el día 8 de junio de 1869. p. 3. www. cepc. gob. es>docs> constituciones>espa>1869 (visto 23-10-2019)

Constitución de la Segunda República de 1931. p.1 www. congreso. es>docu > constituciones>1931>1931_cd (visto23-10-2019)

Constitución Española (2003) Editorial Aranzadi. S.A. Cizur Menor (Navarra). 


\section{Legislación española}

Gaceta de Madrid. Presidencia Consejo de Ministros. Lunes 12 de mayo de 1854. No 6146. p.1.www.boe.es $>$ datos $>$ pdfs $>$ BOE $>1851$. (visto-22-102019)

Fuero de los Españoles de julio de 1945. Jefatura del Estado. Boletín Oficial del Estado (BOE) Madrid. N. Boletín:199. p.358. https: // www. boe.es>datos>pdfs>BOE>1945. (visto 23-10-2019) Ley 44/1967 de 28 de junio, regulando el ejercicio del derecho civil a la libertad en materia religiosa. I Disposiciones Generales Boletín Oficial del Estado (BOE) Madrid. N. Boletín:156. p.9192. DOCUMENTO BOE-A-1967-10943. BOE.es. htps://www.boe.es> Buscar (visto 22-10-2019) (Derogado).

Decreto779/1962, de 20 de abril por el que se aprueban sobre los textos Refundidos de las Leyes del Reino Ley Fundamentales del Reino I. Disposiciones Generales. Boletín Oficial del Estado (BOE) Madrid. N. Boletín:95. p.5253. https: // www. boe.es>boe>días>1967/04/21>pdfs (visto 23-10-2019)

Leyes Penales (1976) Editorial Civitas S.A. Madrid. (Derogado) Ley orgánica 7/1980, de 5 de julio, de libertad religiosa. Jefatura del Estado I Disposiciones generales Boletín Oficial del Estado (BOE) Madrid. N. Boletín 177. p.15955. Documento BOE- A-198015955- BOE.es. htps: //www.boe.es>buscar

Real Decreto 594/2015, de 3 de julio, por el que se regula el Registro de Entidades Religiosas. Ministerio de Justicia I Disposiciones generales Boletín Oficial del Estado (BOE) Madrid. N. Boletín 183.p.66731. Documento BOE- A-2015-8643- BOE.es. htps: //www.boe.es> Calendario>01-08-2015. 


\section{Convenios entre España y la Santa Sede}

Convenio entre la Santa Sede y el Gobierno de España (7 de junio de 1941) p.1.www. fuenterrebo>Textos.- Legales>santa -sede-estado (visto23-10-2019)

Concordato de 1953 entre España y la Santa Sede. p.1.www.vatican.va.>documents>rc_seg-st_19530827_concordato-spagna_sp (visto23-

10-2019).

Instrumento de Ratificación del Acuerdo entre el Estado Español y la Santa Sede sobre asuntos jurídicos, firmado el 3 de enero de 1979 en la Ciudad del Vaticano Jefatura del Estado I. Disposiciones generales. Boletín Oficial del Estado (BOE) Madrid. N. Boletín 300. p.29489 Documento BOE- A-1979-29489 BOE.es. htps: //www.boe.es>buscar

\section{Acuerdos firmados por España en otras confesiones religiosas}

Ley 24/1992, del 10 de noviembre, por la que se aprueba el Acuerdo de Cooperación del Estado con la Federación de Entidades Religiosas Evangélicas de España Jefatura del Estado I. Disposiciones generales. Boletín Oficial del Estado (BOE) Madrid. N. Boletín 272. p.24873 Documento BOE- A-1992-24853 BOE.es. htps: //www.boe.es>buscar

Ley 25/1992, de noviembre, por la que se aprueba el Acuerdo de Cooperación del Estado con la Federación de Comunidades Israelitas en España Jefatura del Estado I. Disposiciones generales. Boletín Oficial del Estado (BOE) Madrid. N. Boletín 272. p.38212 Documento BOE- A- A-1992-24854 BOE.es. htps: //www. boe.es>buscar 
La libertad religiosa en España: un breve estudio en el sistema jurídico- español

Salvador Morales Ferrer

Ley 26/1992, de 10 de noviembre, por la que se aprueba al Acuerdo de Cooperación del Estado con la Comisión Islámica de España. Jefatura del Estado I Disposiciones generales Boletín Oficial del Estado (BOE) Madrid. N. Boletín 272.p.38215 Documento BOE- A-1992-24875 BOE.es. htps: //www.boe. es>buscar

\section{Normas Internacionales}

La declaración Universal de Derechos Humanos 10 de diciembre de 1948. p.3. https://dudlh.es

\section{Jurisprudencia}

Tribunal Constitucional (Pleno) (Ponente: Diez- Picazo y Ponce de León, Luis) (Sentencia núm.24/1982 de 7 de febrero). Rec. 68/1982 Lefebvre. 